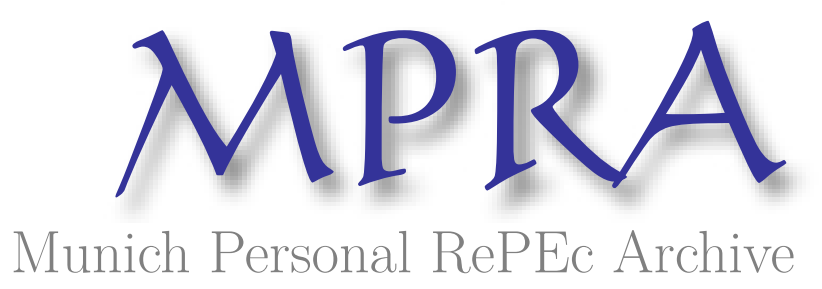

\title{
An analysis of the interdependence of demographic factors, labour effort and economic growth in Ireland
}

Doran, Justin

School of Economics, University College Cork

2012

Online at https://mpra.ub.uni-muenchen.de/48266/

MPRA Paper No. 48266, posted 12 Jul 2013 08:54 UTC 


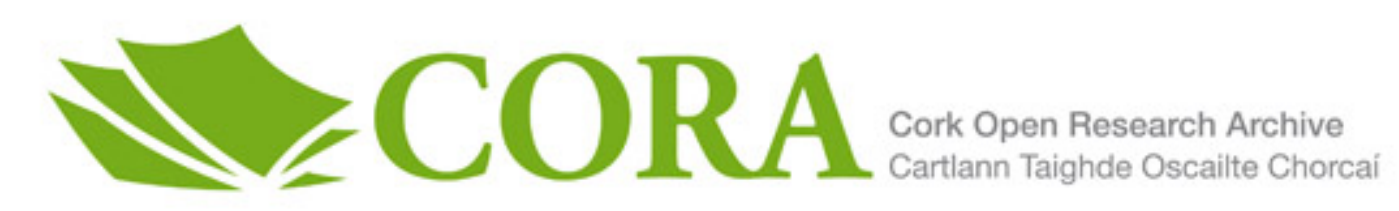

\begin{tabular}{|c|c|}
\hline Title & $\begin{array}{l}\text { An analysis of the interdependence of demographic factors, labour effort } \\
\text { and economic growth in Ireland }\end{array}$ \\
\hline Author(s) & Doran, Justin \\
\hline Publication date & 2012-03 \\
\hline Original citation & $\begin{array}{l}\text { An analysis of the interdependence of demographic factors, labour effort } \\
\text { and economic growth in Ireland", International Journal of Social } \\
\text { Economics, Vol. } 39 \text { Iss: } 3 \text { pp. } 221 \text { - } 237\end{array}$ \\
\hline Type of publication & Article (peer-reviewed) \\
\hline $\begin{array}{l}\text { Link to publisher's } \\
\text { version }\end{array}$ & $\begin{array}{l}\frac{\text { http://dx.doi.org/10.1108/03068291211199387 }}{\text { http://dx.doi.org/10.1108/03068291211199387 }} \\
\begin{array}{l}\text { Access to the full text of the published version may require a } \\
\text { subscription. }\end{array}\end{array}$ \\
\hline Rights & (C) Emerald Group Publishing Limited \\
\hline $\begin{array}{l}\text { Item downloaded } \\
\text { from }\end{array}$ & http://hdl.handle.net/10468/782 \\
\hline
\end{tabular}

Downloaded on 2013-07-12T08:03:20Z 


\title{
An Analysis of the Interdependence of Demographic Factors, Labour Effort and Economic Growth in Ireland
}

\author{
by \\ Justin Doran \\ Department of Economics \\ University College Cork \\ Cork
}

\begin{abstract}
About the Author
Justin Doran is a lecturer in economics in the Department of Economics, University College Cork, Cork, Ireland. He is a member of the Business Strategic Group with the Economics Department. His main research interests lie in the areas of business performance, innovation, regional economics and macroeconomics. Justin Doran can be contacted at: justin.doran@ucc.ie
\end{abstract}

\section{Acknowledgements}

The author would like to thank the following for helpful comments provided on previous drafts of the manuscript: (i) Dr. John Considine of the Department of Economics in University College Cork (ii) the participants at the $8^{\text {th }}$ annual Irish Society of New Economists Conference and (iii) the editor and two anonymous reviewers. 


\title{
An Analysis of the Interdependence of Demographic Factors, Labour Effort and Economic Growth in Ireland
}

\begin{abstract}
Purpose - The purpose of this article is to analyse the effects of a declining birth rate and an increasing old age-population ratio on Ireland's economic output.

Design-Methodology/Approach - This paper utilises data on the birth rate, old-age population ratio, economic output and labour effort of the Irish economy to estimate a vector-autoregressive model. The results of this model are then analysed to test for the presence of Granger causality among these variables. In doing so it is possible to assess whether there are statistically significant causal relationships existing among these factors. Subsequently, impulse response functions are derived from this model in order to assess the magnitude of the causal relationships.

Findings - The results suggest that declining fertility rates and increases in the old-age dependency ratio have a significant impact on labour effort and economic output. Labour effort is also found to explain variation in the fertility rate and economic output. Economic output is found to effect labour effort and the fertility rate.

Social Implications - The results derived in this paper raise interesting policy implications. It is evident that Ireland's declining birth rate and increasing old-age population ratio are creating a demographic situation which will have implications for future economic growth. Policies need to be put in place to mitigate the negative effects these factors will have on Irish growth.

Originality/Value - This paper adopts modern econometric techniques to assess the causal relationships which exist between the demographic and economic factors considered. These have not previously been applied to the Irish situation. In doing this, this paper provides an important insight into the changing dynamics of the Irish economy. Keywords: Demographics, Granger Causality, Economic Growth Paper Type: Research Paper
\end{abstract}




\section{Introduction}

Lee (2003) and Caldwell and Schindlmayr (2003) highlight that there has been a demographic transition from high to low fertility rates within most developed and developing nations. The changing family dynamic towards smaller families is argued by some economists to be a response to changing incentives in the economic climate households find themselves in (Becker 1960; Becker 1981; Barro and Becker 1989; Winegarden and Wheeler 1992; Wang, Yip and Scotese 1994; Caldwell and Schindlmayr 2003). With lower levels of child mortality, increased time devoted to labour effort and increasing returns to productive effort there has been a substantial decrease in the observed fertility rate. In turn, this reduced fertility rate, over time, can translate into an increasingly aging population. This effect can be observed in an increasing number of countries (Lee 2003).

This paper analyses the nature of the causal relationship between the fertility rate, the old-age dependency ratio, labour effort and economic development for Ireland. The time period studied is from 1960 to 2007 . The consideration of these factors is particularly important in the Irish context as, during this time period, Ireland has experienced a vastly changing demographic structure as well as vast economic changes. With further demographic changes predicted, such as an ever increasing aging population, it is vital to consider the impact these changes may have on future economic prosperity. However, the nature of the causal relationship between economic growth and demographics is unclear; and may run both ways. This presents issues for policy makers as a reduction in the fertility rate coupled with an increasing old-age dependency ratio may constrain further economic development.

In order to operationalize this analysis, this paper utilises a vector autoregressive (VAR) model to assess the nature of the Granger causality relationships between the factors considered (Granger 1988; Tonda and Phillips 1993; Tonda and Yamamoto 1995). Further to this, impulse response functions are derived to assess the magnitude and directionality of the causal relationships (Lütkepohl 2005). The use of this approach is possible due to the co-integrating nature of the factors considered (Johansen 1988; Johansen and Juselius 1990; Johansen and Juselius 1992).

The remainder of this paper is structured as follows. Section 2 provides a review of the relevant theoretical concepts underpinning this study. This is followed in Section 3 by an overview of the data considered. Section 4 describes the development of the model utilised. The empirical results derived by this study are discussed in Section 5. The final section concludes and provides policy considerations arising from the empirical investigation.

\section{Review of Existing Literature}

Winegarden and Wheeler (1992) identify that there has been a substantial shift away from the "traditional" family to the "small" family in an increasing number of modern economies. Coupled with a reduction in family size, a reduction in mortality has also been observed which further alters, not only family dynamics, but the aggregate growth rates and age structures of national populations. Nations with declining fertility rates and 
lower levels of mortality are likely to experience an aging process; whereby, over a period of time, their old age dependency ratio increases (Lee 2003). The causes and consequences of these demographic changes are much debated (Barro and Becker 1989; Winegarden and Wheeler 1992; Wang et al. 1994; Hondroyiannis and Papapetrou 2001; Lee 2003). This paper analyses the causes and impact of changing demographics in Ireland on labour effort and economic development. In doing so it acknowledges theoretically that the relationships between factors may have a dual-causality, and, therefore, develops a modeling framework to account for this.

The remainder of this section provides a review of existing literature on economic development and demography. Among the literature there is a disagreement as to the precise nature of the relationship between these factors. Therefore, a review of each of the varying views is provided. Section 2.1 outlines the potential impacts of economic growth on demographic factors. This is followed in Section 2.2 with an outline of how demographic factors may negatively impact economic growth. Finally, Section 2.3 outlines arguments which propose that demographic factors may have a positive effect on economic growth.

\subsection{Economic Growth Impacts on Demographics}

Winegarden and Wheeler (1992) identify that economic changes may impact on the fertility rate through a supply and demand framework (Becker 1960; Becker 1981). It can be argued that fertility may be considered as a maximising process in which the number of children conceived is obtained by maximizing a utility function, subject to the constraint of income and relative prices (Winegarden and Wheeler 1992; Galor and Weil 2000; Narayan 2006). Lee (2003) suggests that child-bearing and raising is time intensive. He holds that technological progress and increasing physical and human capital over time can raise the productivity of labour. This raises the value of time, as increased productivity allows workers to realize higher levels of income than before from time dedicated to labour effort. Given these higher levels of income, the opportunity cost of having children increases, as the time exerted on the bearing and raising of children necessitates the forgoing of potential income (Lee 2003). The increasing opportunity cost of children acts as a disincentive to bearing children and reduces the fertility rate (Hondroyiannis and Papapetrou 2001; Caldwell and Schindlmayr 2003). Therefore, according to this view, increases in economic development should decrease the fertility rate.

Similarly, Wang et al. (1994) suggest that fertility choice can be impacted upon directly by labour effort. They postulate that an individual's time can be divided into a number of productivity activities, such as labour effort, leisure and child-rearing. As all activities are time intensive, choices to increase labour effort reduce the time which can be devoted to child-rearing, thereby reducing the fertility rate. Narayan (2006) argues that increased employment opportunities provides the potential for women to delay the age of reproduction, thereby reducing the number of children conceived. Again this suggests that increased labour effort reduces the fertility rate. 
Ahn and Mira (2002) argue against the concept that economic development has a negative impact on the fertility rate. They propose that the combination of increased participation by females in the workforce and higher wages results in a situation where females in developed countries can purchase child care from market sources. This has the effect of weakening the negative association between economic growth/labour effort and the fertility rate. Ermisch (1989) proposes a model whereby female participation in the labour market initially results in a negative fertility effect but that this reverses once a certain wage treshold is reached. The underpinning principle of the model is that with increased wages it is possible for mothers to shift time they would have spent raising children over to child care which is available from market sources. Thus negating to some extent the choice between labour effort and raising children.

\subsection{Demographics Negatively Impact Growth}

Hondroyiannis and Papapetrou (2001) describe how a declining fertility rate, coupled with an increasing old-age dependency ratio, has the potential to impact on a nation's economic development. They term this a "double aging process", where there is a decreasing active population, relative to total population, due to falling fertility rates and increasing life expectancy. This results in an increasing proportion of the population falling into the dependency category. With a smaller proportion of the population contributing to the work force the potential for economic growth is reduced. Regarding labour effort, Hondroyiannis and Papapetrou (2001) and Caldwell and Schindlmayr (2003) suggest that the choice to invest in child-rearing may have a negative impact in female participation in the workforce. This arises due to a reduction in the time an individual can invest in labour effort.

It is important to also note that the changing demographics are not confined merely to a reduction in the fertility rate. Many economies are also experiencing an aging population; which may have ramifications for further economic development (Hondroyiannis and Papapetrou 2001; Hondroyiannis 2010). This situation arises due to a low fertility rate restricting growth in the working aged population and, over time, increasing the old-age dependency ratio (Lee 2003). This can have negative impacts on economic development through reducing the available workforce and increasing the level of dependency (Hondroyiannis and Papapetrou 2001; Prskawetz, Kögel, Sanderson and Scherbov 2007). Further to this, an aging population may also reduce the labour effort available within the economy (Caldwell and Schindlmayr 2003).

\subsection{Demographics Positively Impact on Growth}

Prskawetz et al. (2007) suggests that a declining fertility rate can have a positive impact on economic growth. Bloom and Williamson (1998) identify two mechanisms through which this can occur. Both mechanisms revolve around the effect a declining fertility rate has on the ratio of working age population to total population. As the fertility rate falls, the proportion of people in the working aged category relative to the total population increases. The first mechanism is that the increasing ratio of working age population to total population implies an increase in the ratio of "producers" to "consumers". Essentially more individuals are producing in the economy versus the 
number which are just consuming. This drives up the total output in an economy, rising living standards for all.

The second mechanism is behavioral effects, where a rising ratio of working age population to total population implies a falling dependency ratio which in turn increases aggregate savings (Bloom, Canning and Graham 2003). The rationale behind this is that in countries with a high fertility rate there are a large number of dependents which consume the income of the working age population. Where fertility rates are lower there are less dependents consuming this income, facilitating higher levels of savings (Kelley and Schmidt 1996). These higher savings levels, in line with standard economic growth theories such as the Solow (1956) model, translate into higher levels of economic growth.

Following from the above discussions, demographic changes in the fertility rate and oldage dependency ratio can impact on, and be impacted by, economic development and labour effort (Barro and Becker 1989; Wang et al. 1994; Lee 2003). The interrelatedness of these factors presents difficulties in the disentanglement of the causal effects of each. Therefore, in order to ascertain the consequences of the changing economic development, labour effort and demography in Ireland over the period 1960 to 2007, a model is developed which allows for an analysis of the causal impact of each variable on the other.

\section{Data}

\subsection{Data Sources}

In order to address the questions posed by this paper, data on fertility, old-age dependence, labour effort and economic development are required. These data, for the time period 1960 to 2007, are assembled from a number of sources. Data on Irish fertility rates is obtained from the World Bank's World Development Indicators data set (World Bank 2010); and is defined as the average births per woman. The old-age dependency ratio is calculated from data obtained from the Irish Central Statistics Office (CSO 2009); based on the proportion of the population aged between 20 and 64 to those aged over 65 . Labour effort is proxied for by the total hours worked in the economy, which is obtained from the Total Economy Database (The Conference Board 2010). Real gross domestic product (GDP) per capita is used to measure economic development and data on this is also obtained from the Total Economy Database. It is expressed in constant 2009 level US\$. For ease of presentation the variables are defined as; fertility ratio (FERT), old-age dependency ratio (DPR), total hours worked (THW) and real GDP per capita (RGDP).

The use of these variables is consistent with the international literature surrounding this area (Wang et al. 1994; Hondroyiannis and Papapetrou 2001; Hussain, Malik and Hayat 2009; Hondroyiannis 2010).

\subsection{Describing the Irish Data}

Figure 1 plots the fertility rate and old-age dependency ratio for Ireland. Over the time period studied both have fallen rapidly. The fertility rate has declined from just under four births per woman in the 1960s to under two births per woman by 1990 . After 1990 the fertility rate has stabilized and only fluctuated slightly around this value. The decline in the old-aged dependency ratio has been more consistent. Starting from the mid 1960s, 
Ireland's old-aged dependency ratio has fallen from approximately 24 percent to just under 18 percent. The movement of these variables represent a time in Irish economic history when the country experienced both declining fertility and declining old-age dependency. However, this decline in the old-age dependency ratio is not expected to continue and the ratio is expected to rise rapidly in the future. See Appendix 1 for a disaggregated view of Irish population by age category.

Take in Figure (1)

Figure 2 displays the economic changes which took place in Ireland over this time period. From 1960 to 1990 total hours worked in Ireland decreased slightly. However, after 1990 there was a dramatic increase in the total hours worked. This increase coincides with the "Celtic Tiger" period of Irish economic growth and the subsequent growth in domestic demand; both of which resulted in large increases in employment and immigration. Economic growth has followed a similar path. From 1960 to 1990 the Irish economy experienced moderate growth, however, after 1990 economic growth accelerated rapidly. Again, this can be attributed to the economic changes occurring in Ireland during this time. See Kennedy (2001) for a concise discussion on the cause of Irish economic growth during this time period.

Take in Figure (2)

\section{Modeling the Causal Relationship}

In order to analyse the relationship between fertility, old-age dependency, labour effort and economic development a vector autoregressive (VAR) model is estimated. This facilitates the use of a test for Granger causality and the derivation of impulse response functions from the model (Granger 1988; Lütkepohl 2005). The use of these methods allows for the causal impact of each variable on the other to be distinguished. However, before this can be undertaken the data must be subjected to a number of tests and manipulations so as to ensure the model specification is correct.

\subsection{Unit Root Tests}

The first stage of the analysis is to ascertain whether the variables considered possess a unit root. In line with Hondroyiannis and Papapetrou (2001) and Awoluse (2005) both an Augmented Dickey-Fuller (ADF) test and a Phillips and Perron (PP) test are employed (Dickey and Fuller 1979; Phillips and Perron 1988). The combination of these tests allows for a robust analysis of the degree of integration of the variables considered. In order to determine the specification of the lag structure required for the test equations, auto-correlograms are derived and analysed.

\subsection{Analysing the Lag Structure of the Vector Error Correction (VEC) Model}

As time series data are utilised there is the potential that regressing one variable on another may result in a spurious estimation due to an underlying trend in the data. However, should the variables be co-integrated, a long run relationship exists between them and spurious regressions are avoided. Therefore, this paper tests for the presence of co-integrating relationships between the variables utilised. However, before 
implementing the co-integration test the correct lag structure must be identified. To accomplish this three tests are used; these are the Aikaike information criterion (AIC), Hannan and Quinn information criterion (HQIC) and Schwartz's Bayesian information criterion (BIC) (Aikaike 1974; Schwarz 1978; Hannan and Quinn 1979). The principles behind these tests are that they measure the discrepancy between the given model and the true model and select the lag length which minimizes this discrepancy (Lütkepohl 2005). The lag length, as indicated by these measures, is included in the subsequent statistical analysis which requires a lag structure.

\subsection{Co-integration Tests}

As outlined above when considering time series data which may possess a unit root there is the potential of spurious correlations between the variables. Therefore, in order to ensure the correct model specification is adopted, this paper investigates whether a cointegrating relationship exists among the variables considered. While Engle and Granger (1987) provide a useful test for co-integration, it is limited to the analyse of pair-wise cointegrating relationships. As more than two variables are analysed in this paper, and there is a postulated co-integrating relationship between all of them, a test which can account for this is required. Therefore, the Johansen-Juselius co-integration test is utilised (Johansen 1988; Johansen and Juselius 1990; Johansen and Juselius 1992). This test is based on the VEC model given as:

$$
\Delta X_{t}=\mu+\sum_{i=1}^{p-1} \Gamma_{i} \Delta X_{t-i}+\Pi X_{t-1}+\varepsilon_{t}
$$

Where $X_{t}$ is a ( $\left.n \times 1\right)$ column vector of $\mathrm{p}$ variables, $\mu$ is a ( $\left.\mathrm{n} \times 1\right)$ vector of constant terms, $\Pi$ represent coefficient matrices, $\Delta$ is a difference operator, i denotes the lag length and $\varepsilon_{t}$ is the error term. The coefficient matrix $\Pi$ is known as the impact matrix and it contains information about the long-run relationships.

Johansen and Juselius' (1990) methodology requires the estimation of equation (1) and tests for co-integrating relationships using the trace test statistic and the maximum eigenvalue test. The null hypothesis of the trace statistic is that there are no more than $r$ co-integrating relationships. The alternative hypothesis of the trace statistic is that the number of co-integrating relationships is larger than the number $r$ assumed under the null hypothesis. Repeated testing of alternative null hypotheses allows for the identification of the correct number of co-integrating relations between the variables analysed.

\subsection{Estimating the Vector Autoregressive (VAR) Model and testing for Granger Causality} Once the order of co-integration has been identified this paper estimates a VAR model. A VAR model is estimated as, while causality can be identified from the VEC model, this describes the short term relationship between the variables. By utilising a VAR model it is possible to analyse the long term co-integrating relationship between the variables (Doyle 2001). A test for Granger causality is applied to the VAR model estimated as outlined by Tonda and Phillips (1993), Tonda and Yamamoto (1995) and Zapata and Rambaldi (1997). 
This initially involves the estimation of the VAR model expressed in equation (2).

$$
y_{t}=\alpha_{0}+\beta_{1} y_{t-1}+\ldots+\beta_{\rho} y_{t-\rho}+v_{t}
$$

In the above VAR model four variables are considered and are specified as linear functions of $\rho$ of their own lags and $\rho$ lags of the other three variables. Where $y_{t}$ is a matrix of ( $\mathrm{nx} 4$ ) variables, $\alpha$ is a ( $\mathrm{nx} 1)$ vector of constant terms, $\beta$ is a ( $\mathrm{nx} 4)$ matrix of coefficients, $\rho$ is the lag length and $v_{t}$ is the error term.

To test for Granger causality in a VAR model a series of Wald tests or likelihood tests of linear restrictions of the lagged coefficients of the independent variables can be employed (Tonda and Phillips 1993; Tonda and Yamamoto 1995; Zapata and Rambaldi 1997). This allows for a test of the null hypothesis that the lagged values do not predict the dependent variable; thereby indicating that they do not Granger cause the dependent variable (Granger 1988).

\subsection{Impulse Response Functions}

In order to expand on the tests of Granger causality by considering the magnitude of the causal effects, impulse response functions are derived from the estimated VAR model. These functions allow for an analysis of the response of variables to shocks caused by other variables in the system (Lütkepohl 2005). In this instance the orthogonalized impulse response functions are obtained from the VAR model and plotted. The use of impulse response functions allows for an analysis of the response of variables to shocks within the system. The effect of each variable on the others can be isolated and interpreted and the directionality of the relationship also identified. (Wang et al. 1994; Masih and Masih 1999; Hondroyiannis and Papapetrou 2001).

\section{Empirical Results}

\subsection{The Presence of Unit Roots}

Table 1 presents the results of the ADF and PP tests of stationarity for each variable. As would be expected, the variables are not stationary in their levels. Both the ADF and PP tests indicate that FERT, DPR, THW and RGDP are non-stationary. However, when first differences are taken the ADF and PP tests reject the null hypothesis of non-stationarity; suggesting that $\triangle \mathrm{FERT}, \triangle \mathrm{DPR}, \triangle \mathrm{THW}$ and $\triangle \mathrm{RGDP}$ are stationary. Combined, these results suggest that the variables considered are integrated of order one.

Table 1: Tests for Unit Root

\begin{tabular}{lrr}
\hline & DF & PP \\
\hline LFERT & -0.733 & -1.495 \\
LDEP & -0.619 & -0.33 \\
LHOURS & 0.404 & 0.002 \\
LRGDP & -1.304 & -1.124 \\
$\Delta$ LFERT & $-3.056^{* * *}$ & $-2.788^{* * *}$ \\
$\Delta$ LDEP & $-1.678^{*}$ & $-1.678^{*}$
\end{tabular}


existence of at least one co-integrating relationship. Further to this, the trace statistic suggests that the null hypothesis that there is more than one co-integrating relationship is rejected; implying that there is no more than one co-integrating relationship. Therefore, it is concluded that only one co-integrating system exists.

Table 3: Testing for Co-Integration

\begin{tabular}{|c|c|c|c|c|c|}
\hline $\begin{array}{r}\text { Maximum } \\
\text { Rank }\end{array}$ & Parameters & LL & Eigenvalue & $\begin{array}{r}\text { Trace } \\
\text { Statistic }\end{array}$ & $\begin{array}{r}\text { Critical } \\
\text { Value }\end{array}$ \\
\hline 0 & 20 & 535.74 & & 52.67 & 47.21 \\
\hline 1 & 27 & 547.24 & 0.3934 & $29.67^{*}$ & 29.68 \\
\hline 2 & 32 & 554.23 & 0.2619 & 15.70 & 15.41 \\
\hline 3 & 35 & 559.87 & 0.2174 & 4.42 & 3.76 \\
\hline 4 & 36 & 562.08 & 0.0917 & & \\
\hline
\end{tabular}

Note 1: * Denotes the optimal co-integration rank as indicated by the test.

\subsection{Granger Causality}

Table 4 presents the results of the tests for Granger causality. This is implemented through the use of the Wald test statistic; with the null hypothesis suggesting no causal relationship exists (Granger 1988). The null hypothesis of non-causality is rejected for a number of the variables considered. The directionality and magnitude of this causality is not discussed further here but is analysed and described in Section 5.5 when considering the impulse response functions.

Regarding the effects of the fertility rate, the null hypothesis that the fertility rate does not Granger cause real GDP per capita can be rejected. This finding provides support for the hypothesis proposed by Prskawetz et al. (2007); that the fertility rate, through reducing the youth dependency ratio, can have implications for the rate of economic development. However, the null hypothesis can not be rejected for the effects of the fertility rate on the dependency ratio and total hours worked. This finding of no causal relationship between the fertility rate and total hours worked is counterintuitive. It would have been expected that the decision to have children would reduce the time with which individuals would have to devote to labour effort (Barro and Becker 1989; Galor and Weil 2000). However, a possible explanation of this insignificant effect is proposed by Ahn and Mira (2002) who suggest that the increasing availability of market based childcare and the increasing wages available to women have resulted in a weakening of the tradeoff between work and raising children. Therefore, women do not face the same time constraints as before and can choose to both have children (who can be taken care of through market based child care) and engage in the labour force.

Table 4: Granger Causality Test Results

\begin{tabular}{lr}
\hline $\mathrm{H}_{0}$ & Wald Statistic \\
\hline FERT $\rightarrow$ FERT & n.a. \\
FERT $\rightarrow$ DRP & 3.391 \\
FERT $\rightarrow$ THW & 4.243 \\
FERT $\rightarrow$ RGDP & $8.7901^{* *}$
\end{tabular}




\begin{tabular}{lr} 
DPR $\rightarrow$ FERT & 1.3512 \\
DPR $\rightarrow$ DPR & n.a. \\
DPR $\rightarrow$ THW & $9.7391^{* * *}$ \\
DPR $\rightarrow$ RGDP & $14.109 * * *$ \\
THW $\rightarrow$ FERT & $10.035^{* * *}$ \\
THW $\rightarrow$ DPR & 1.8136 \\
THW $\rightarrow$ THW & n.a. \\
THW $\rightarrow$ RGDP & $7.6644^{* *}$ \\
RGDP $\rightarrow$ FERT & $5.3804 *$ \\
RGDP $\rightarrow$ DPR & 2.1032 \\
RGDP $\rightarrow$ THW & $5.9107^{* *}$ \\
RGDP $\rightarrow$ RGDP & n.a. \\
\hline \hline Note 1: $\rightarrow$ represents “does not cause" & \\
$2:$ & $*$ reject null hypothesis at 10\% significance \\
& level, ** reject null hypothesis at $5 \%$ \\
& significance level and *** reject null \\
& hypothesis at 1\% significance level.
\end{tabular}

For the old-age dependency ratio it is possible to reject the null hypothesis of noncausality for total hours worked and real GDP. This suggests that, as expected, the dependency ratio has a causal influence on these two variables (Hondroyiannis and Papapetrou 2001). However, it is not possible to reject the null hypothesis that the oldage dependency ratio does not cause the fertility rate.

Turning to total hours worked the null hypothesis of non-causality for the fertility rate and real GDP is rejected. This finding is in line with the theory suggested by Becker (1960), Wang et al. (1994) and Hondroyiannis and Papapetrou (2001) and suggests that the number of hours worked can impact on output and fertility choice. The results also suggest that total hours worked does not Granger cause the dependency ratio.

Finally, it can be observed that real GDP per capita Granger causes the fertility rate and the total hours worked. A significant causal effect of GDP per capita on the fertility rate is consistent with Winegarden and Wheeler's (1992) proposition that the decision on the number of children to conceive is obtained by maximizing a utility function subject to an income constraint, with GDP per capita proxying as the income constraint in this case. Regarding GDP per capita and total hours worked, Lee (2003) argues that individuals respond to incentives, and that as the reward from working increases (GDP per capita) people will choose to engage more in the labour force.

\subsection{Orthogonalized Impulse Response Functions}

Progressing from the analysis of Granger causality discussed above the orthogonalized impulse response functions are presented in Figure 3. These allow for a discussion of the magnitude and directionality of the causality identified. Discussion will focus on the variables which were found to have a significant Granger causal relationship. 
Row one of Figure (3) shows the fertility rate as the impulse. A positive fertility shock can be observed to have a negative impact on economic output. This suggests that as more resources are devoted to child-rearing, this has a negative impact on output. This is consistent with Prskawetz et al. (2007) assertion that by reducing the young-age dependency ratio, through a reduction in the fertility rate, more opportunities are provided for economic growth.

The second row of graphs in Figure 3 relates to the impulse response of the variables to a shock in the old-age dependency ratio. An increase in the old-age dependency ratio results in a decrease in the total hours worked. This result may be a manifestation of a reduction in the proportion of the population in the working age category. As this category decreases, due to depletion accruing from retirements, the potential pool of workers which can dedicate time to labour effort decreases. Finally, an increase in the old-age dependency ratio results in a decrease in output. This negative impact of an increasing old-age dependency ratio on economic output may arise due to a reduction in a nation's ability to fully capitalize on its economic potential due to an insufficient working age population. These results are generally consistent with the findings of Hondroyiannis and Papapetrou (2001) and suggests that an aging population can have serious implications for future economic development.

The third row in Figure 3 relates to the effect of a shock to the system from total hours worked. A positive total hours worked shock increases the fertility rate. This result is surprising given the a priori expectations that workers devote their time between childrearing and labour effort. This result is inconsistent with that presented by Wang et al. (1994) and Hondroyiannis and Papapetrou (2001). However, it may be a manifestation of the decision by women to postpone child-rearing until later in life due to increased employment opportunities. This would result in initially higher levels of labour effort by women followed by a subsequent transfer of time to child-rearing. Finally, a positive total hours worked shock has a positive effect on economic output. This is expected as when labour effort increases it would be anticipated that economic output would also increase. The more time that is allocated to productive effort the more output that would be produced (Lee 2003).

The fourth row of Figure 3 presents the graphs of the impact of an economic output shock on each variable in the system. Output was found to Granger cause the fertility rate and total hours worked. It can be observed that a positive output shock results in a slight rise in the fertility rate. This increase is counter to Winegarden and Wheeler's (1992) proposition that an increase in economic prosperity results in a decrease in the fertility rate. One possible explanation for this result is proposed by Ahn and Mira (2002). They note that while increases in income have been associated with decreases in fertility rates in most developing countries over the last number of decades there has been a number of studies which have documented a weakening of this relationship. Ahn and Mira (2002) also find a positive association between economic growth and fertility from 1980 
onwards in their analysis of a panel of OECD countries. They conclude that the increased availability of market based child care and the rising income effect of wages, at high levels of the female wage, mitigate what once was a trade off between employment and children.

The positive output shock of GDP on total hours worked is consistent with Wang et al. (1994), who also find that in higher levels of economic output results increased labour effort. Wang et al. (1994) explain this effect by suggesting that the higher wage rates available when economic output is growing entices more people into the labour market, thus causing an increase in labour effort.

\section{Conclusion and Policy Implications}

This paper analyses the causal linkages between demographic changes in Ireland and labour effort and economic development. In doing so it provides an insight into how the changing demographics of Irish society may impact on future economic growth. An increasing old-age dependency ratio is found to reduce economic output while a declining fertility rate is found to increase economic output. It also highlights the inter-relatedness of the fertility rate, labour effort and the old age dependency ratio and their impact on the economic development of Ireland. This is accomplished through the estimation of a VAR model to analyse the Granger causalities between the variables considered and the generation of orthogonalized impulse response functions.

Tests of Granger causality indicate that the fertility rate has a significant causal impact on a nation's economic development with the impulse response function indicating that a positive fertility shock causes a decrease in economic output. This finding is consistent with that of Prskawetz et al. (2007), who suggest that a decrease in the fertility rate reduces the young-age dependency ratio, thereby providing more opportunities for economic growth. This suggests that the declining fertility rate should not be of concern to policy makers as it will not have an immediate negative impact on future economic development. A lower fertility rate may contribute to economic development by reallocating resources away from child rearing and into the workforce.

However, over a longer term horizon this declining fertility rate may have serious ramifications through another demographic transformation; that of an increased old-age dependency ratio. Caldwell and Schindlmayr (2003) suggest that the fertility rate in modern economies is falling below the replacement rate; resulting in an ever increasing proportion of the population falling into the old-age category. Indeed, as can be observed in Appendix 1, this aging effect is occurring in Ireland over the time period studied. With a decrease in the percentage of the population between the ages of 15 and 24 and an increase in those aged 35 to 64 and aged over 65.

The results discussed earlier in this paper point to the negative impact an increasing oldage dependency ratio can have on other demographic factors and on labour effort and economic development. The Granger causality tests indicate that the old-age population ratio has a causal influence on total hours worked and on economic output with the impulse response factors suggesting that increases in the old-age dependency ratio reduce 
the total hours worked in an economy and economic output. These results suggest that the aging process, predicted to be experienced by Ireland in the near future, will have negative implications for future labour effort and economic development.

Overall these results point to the conclusion that, while in isolation the decreasing Irish fertility rate has no negative implications for economic development, when viewed in conjunction with its contribution to an aging population, this trend should be worrying for policy makers. Evidence presented in this paper indicates that an increasing old-age dependency ratio has a negative impact on both the labour effort exerted within an economy and on economic development. This suggests a need for policy makers to plan for the problems associated with an increasingly aging population; such as ensuring sufficient funds for the provision of State pensions and health care as well as considering how to promote economic growth and engagement in the labour force.

As noted by Botman and Iakova (2007) careful planning can help to avoid potential problems associated with an aging population. It was with this foresight in mind that the Irish government established the National Pension Reserve Scheme. This was established as an investment fund designed to provide for future pension requirements. However, this fund has been depleted in recent years to shore up the large government budget deficits experienced during the financial crisis. This has resulted in the fund becoming insufficient to meet future pension needs. Substantial re-investment will be required in this fund to ensure sufficient reserves are amassed to provide for the existing planned pension entitlements.

To mitigate for the negative impact of an increasing old-age dependency ratio on economic growth Johnson and Zimmermann (1992) propose that the retirement age could be increased and that the economy may seek to attract workers from other countries. Ireland is already progressing down both of these paths, increasing the retirement age for those currently in the workforce and encouraging immigration through engagement with the European Union. These two factors could encourage more engagement in the workforce, reducing the old-age dependency ratio and mitigating for the negative effect an increasingly aging population may have on economic growth. 


\section{References}

Ahn, N. and P. Mira (2002). A Note on the Changing Relationship Between Fertility and Female Employment Rates in Developed Countries. Population Economics 15(4): $667-682$.

Aikaike, H. (1974). A New Look at the Statistical Model Identification. IEEE Transactions on Automatic Control 19(6): 716-723.

Awoluse, T. (2005). Exports, economic growth and causality in Korea. Applied Economics Letters 12(11): 693 - 696.

Barro, R. and G. Becker (1989). Fertility Choice in a Model of Economic Growth. Econometrica 57(2): 481-501.

Becker, G., Ed. (1960). An Economic Analysis of Fertility. Demographic and Economic Change in Developed Countries, Princeton University Press).

Becker, G. (1981). A Treatise on the Family.(Cambridge, Havard University Press).

Bloom, D., D. Canning, et al. (2003). Longevity and Life Cycle Savings. Scandinavian Journal of Economics 105(9): 319 - 338.

Bloom, D. and J. Williamson (1998). Demographic Change and Economic Growth in Asia. World Bank Economic Review 12: 419 - 455.

Botman, D. and D. Iakova (2007). Policy Challenges of Population Aging in Ireland. IMF Working Paper Series 07(247).

Caldwell, J. and T. Schindlmayr (2003). Explanations of the Fertility Crisis in Modern Societies: A Search for Commonalities. Population Studies 57(3): 241-263.

CSO. (2009). "Population Estimates." Retrieved 20-10-2010, from http://www.cso.ie/px/pxeirestat/Dialog/varval.asp?ma=PEA01\&ti=Population+Es timates+(Persons+in+April)+(Thousand)+by+Sex,+Age+Group+and+Year\&path $=. . /$ Database/Eirestat/Population\%20Estimates/\&lang=1.

Dickey, D. A. and W. A. Fuller (1979). Distribution of the Estimators for Autoregression Time Series with a Unit Root. Journal of the American Statistical Association 74: 427-431.

Doyle, E. (2001). Export-Output Causality and the Role of Exports in Irish Growth: 1950 - 1997. International Economic Journal 15(3): 31-54.

Engle, R. F. and C. W. Granger (1987). Cointegration and Error Correction: Representation, Estimation, and Testing. Econometrica 55: 251-276.

Ermisch, J. (1989). Purchased Child Care, Optimal Family Size and Mother's Employment: Theory and Econometric Analysis. Journal of Population Economics 2(2): 79 - 102.

Galor, O. and D. Weil (2000). Population, Technology and Growth: From Malthusian Stagnation to the Demographic Transition and Beyond. The American Economic Review 90(4): 806-828.

Granger, C. W. (1988). Developments in a Concept of Causality. Journal of Econometrics 39(1-2): 199-211.

Hannan, E. J. and B. G. Quinn (1979). The Determination of the Order of an Autoregression. Journal of the Royal Statistical Society 41: 190-195.

Hondroyiannis, G. (2010). Fertility Determinants and Economic Uncertainty: An Assessment Using European Panel Data. Journal of Family and Economic issues 31(1): 33-50. 
Hondroyiannis, G. and E. Papapetrou (2001). Demographic Changes, Labour Effort and Economic Growth: Emperical Evidence from Greece. Journal of Policy Modeling 23: 169-188.

Hussain, S., S. Malik, et al. (2009). Demographic Transition and Economic Growth in Pakistan. European Journal of Scientific Research 31(3): 491-499.

Johansen, S. (1988). Statistical and Hypothesis Testing of Cointegrating Vectors. Journal of Economic Dynamics and Control 12: 231-254.

Johansen, S. and K. Juselius (1990). Maximum Likelihood and Inference on Cointegration: With Applications to the Demand for Money. Oxford Bulletin of Economics and Statistics 52: 169-210.

Johansen, S. and K. Juselius (1992). Testing Structural Hypotheses in a Multivariate Cointegration Analysis at the Purchasing Power Parity and the Uncovered Interest Parity for the UK. Journal of Econometrics 53: 211-244.

Johnson, P. and K. Zimmermann (1992). Labour markets in an ageing Europe.(UK, Cambridge University Press).

Kelley, A. and R. Schmidt (1996). Saving, Dependency and Development. Journal of Population Economics 9(6): 365 - 386.

Kennedy, K. (2001). Economic Growth in Ireland: Where has it Come From, Where is it Going? Journal of the Statistical and Social Inquiry Society of Ireland 60: 123139.

Lee, R. (2003). The Demographic Transition: Three Centuries of Fundamental Change. The Journal of Economic Perspectives 17(4): 167-190.

Lütkepohl, H. (2005). New Introduction to Multiple Time Series Analysis.(New York, Springer).

Masih, A. and R. Masih (1999). Is a Significant Socio-Economic Structural Change a Pre-Requisite for Initial Fertility Decline in the LDCs? Evidence from Thailand Based on a Multivariate Cointegration/Vector Error Correction Modelling Approach. Journal of Population Economics 12(3): 463-487.

Narayan, P. (2006). Determinants of Female Fertility in Taiwan, 1966-2001: Empirical Evidence from Cointegration and Variance Decomposition Analysis. Asian Economic Journal 20(4): 393-407.

Phillips, P. C. B. and P. Perron (1988). Testing for a Unit Root in Time Series Regression. Biometrika 75: 335-346.

Prskawetz, A., T. Kögel, et al. (2007). The Effects of Age Structure on Economic growth: An Application of Probabilistic Forecasting to India. International Journal of Forecasting 23: 587-602.

Schwarz, G. (1978). Estimating the Dimension of a Model. The Annals of Statistics 6(2): 416-464.

Solow, R. (1956). A Contribution to the Theory of Economic Growth. The Quarterly Journal of Economics 70(1): 65 - 94.

The Conference Board (2010). Total Economy Database.

Tonda, H. Y. and P. C. B. Phillips (1993). Vector Autoregressions and Causality. Econometrica 61(6): 1367-1393.

Tonda, H. Y. and T. Yamamoto (1995). Statistical Inference in Vector Autoregressions with Possibly Integrated Processes. Journal of Econometrics 66(1): 225-250. 
Wang, P., C. K. Yip, et al. (1994). Fertility Choice and Economic Growth: Theory and Evidence. The Review of Economics and Statistics 76(2): 255-266.

Winegarden, C. R. and M. Wheeler (1992). The Role of Economic Growth in the Fertility Transition in Western Europe: Econometric Evidence. Economica 59: 421-435. World Bank (2010). World Development Indicators.

Zapata, H. O. and A. N. Rambaldi (1997). Monte Carlo Evidence on Cointegration and Causation. Oxford Bulletin of Economics and Statistics 59(2): 285-298. 
Figure 1: Demographic Changes in Ireland 1960 - 2007

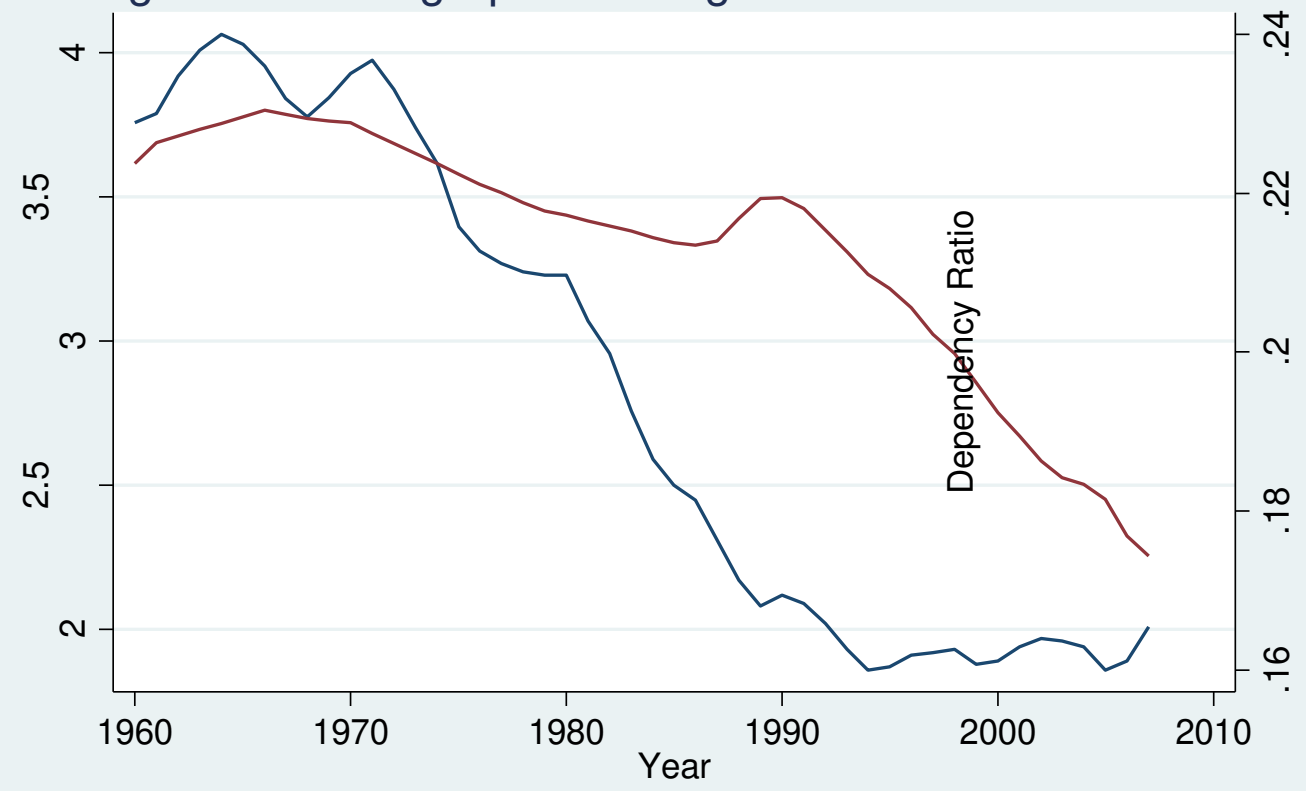

Fertility Rate

Dependency Ratio

Figure 2: Economic Changes in Ireland 1960 - 2007

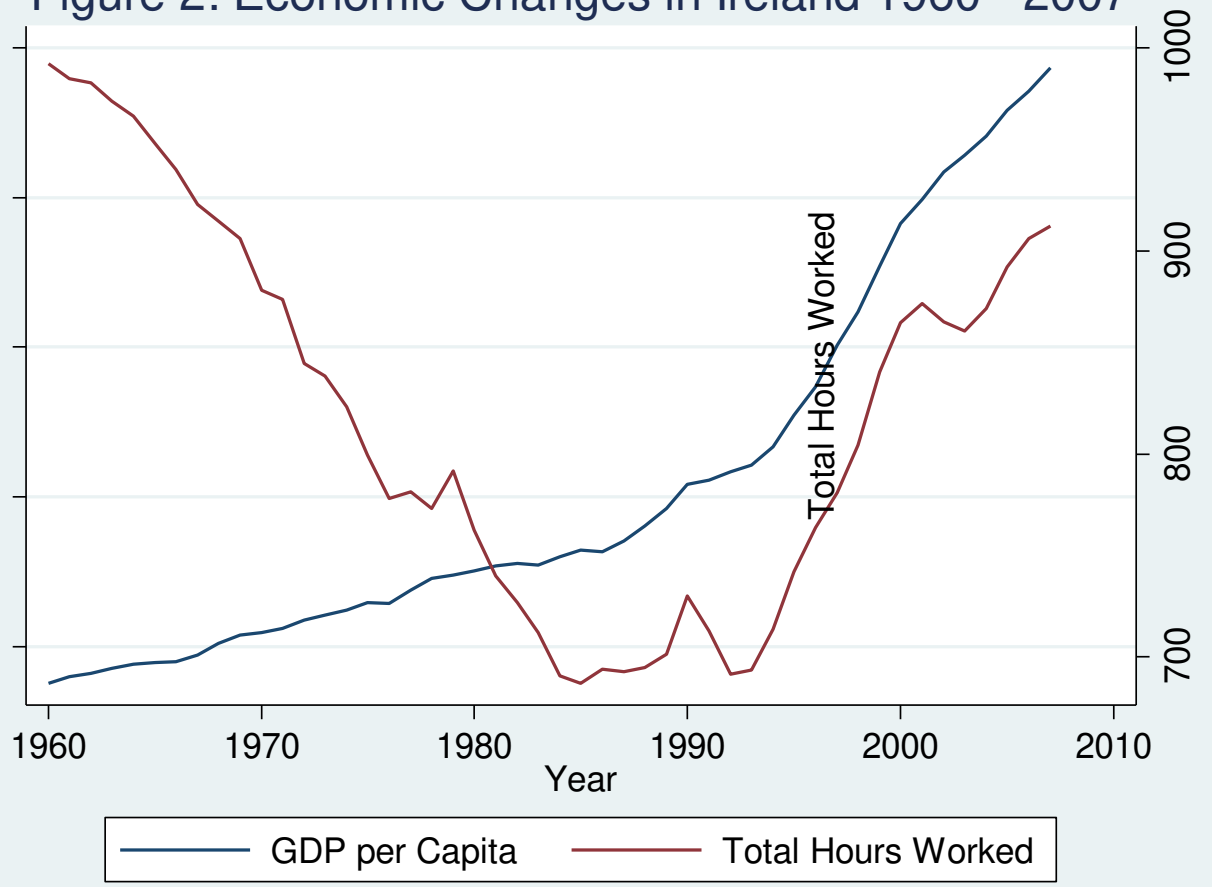




\section{Figure 3: Orthogonalized IRFs from VAR Model}

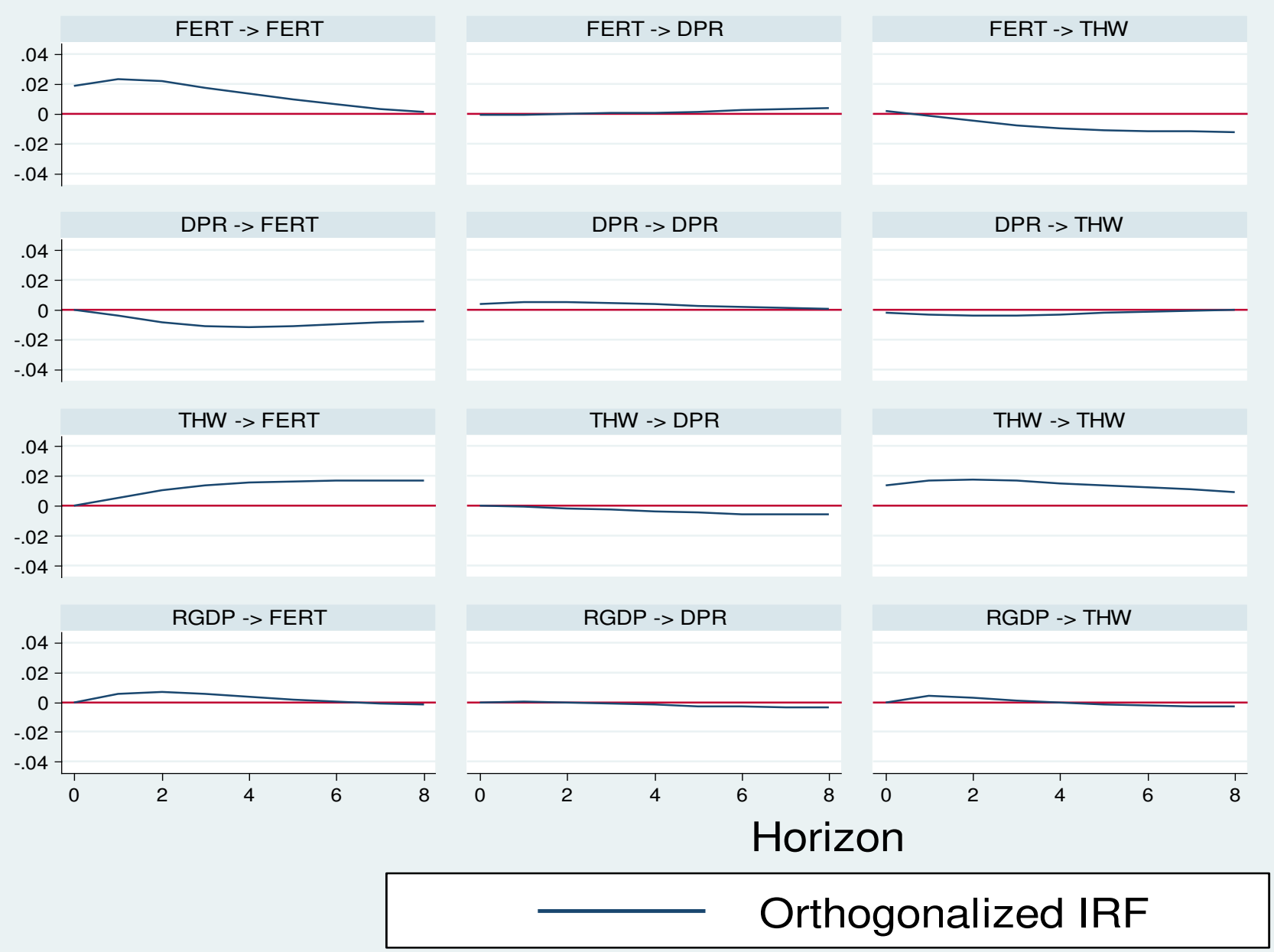

FERT ->RGDP

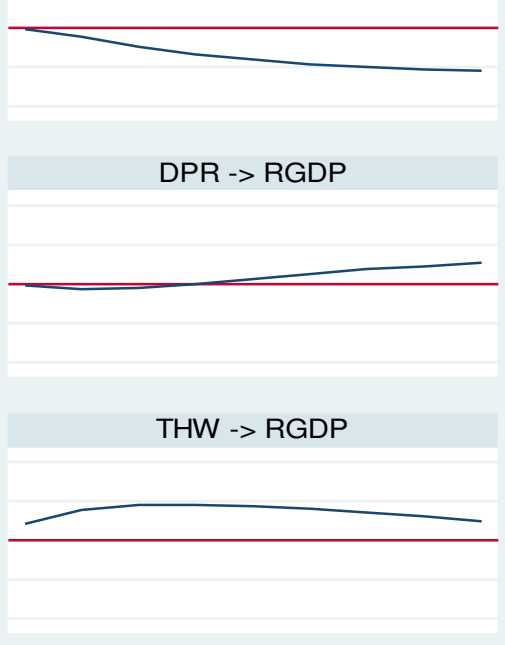

RGDP -> RGDP

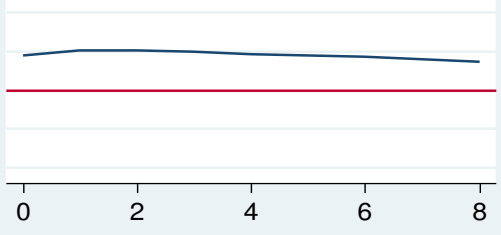

Graphs by Impulse Variable and Response Variable 


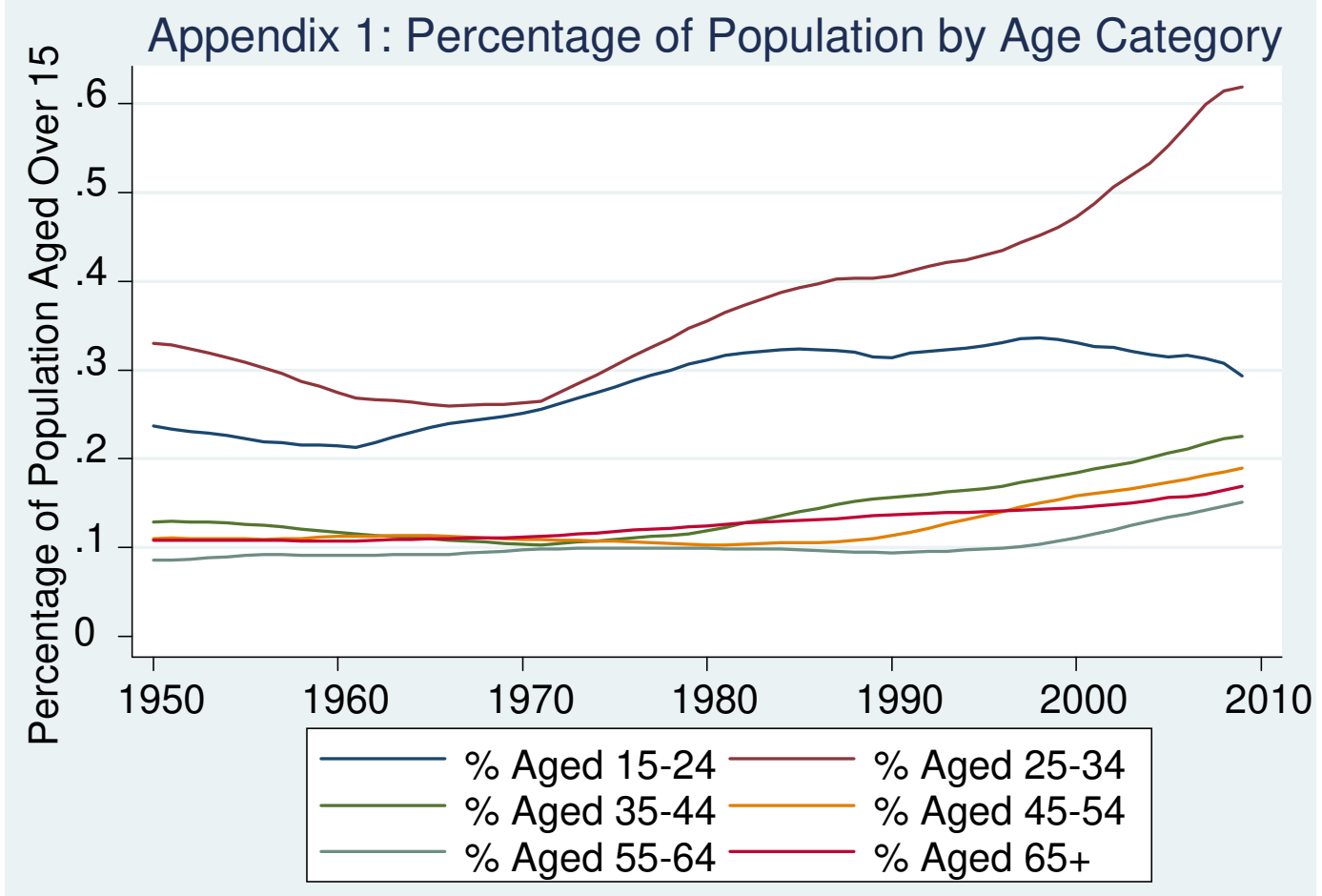

